\title{
Associations and recognition learning 1
}

GORDON WOOD, Michigan State University, East Lansing, Mich. 48823

$A$ paired-associate- (PA) to-recognition transfer task was used to assess whether associations among words can influence recognition learning. Positive transfer was obtained when the correct words for recognition were presented for $P A$ learning, and negative transfer was obtained when the incorrect words for recognition were presented for $P A$ learning. The associations formed during $P A$ learning did not influence recognition learning.

Recently, investigators have attempted to clarify whether recall and recognition involve the same or different processes by determining what variables, if any, differentially influence recall and recognition performance. Organization is believed by some (e.g., Kintsch, 1968) to influence retrieval processes only and therefore is not expected to have any effect on recognition, which, according to Kintsch, does not require retrieval. Although organization influences recall, it is not clear whether or not organization has an influence on recognition (cf. Bower, Clark, Lesgold, \& Winzenz, 1969; Kintsch, 1968; Mandler, Pearlstone, \& Koopmans, 1969). The present study was designed to investigate further whether or not recall and recognition involve separate processes. Since associations established during paired-associate (PA) learning can influence free-recall performance (cf. Wood, 1969), an attempt was made to determine if associations can influence recognition.

The issue of whether or not associations among items influence recognition learning is similar to a controversy that has resulted from attempts to test a prediction that follows from verbal-discrimination learning theory (Ekstrand, Wallace, \& Underwood, 1966). In brief, the theory predicts that a list of intrapair associates should be more difficult to learn than a control list composed of words that are associatively unrelated. Palermo \& Ullich (1968) found that the difficulty of the verbal-discrimination task increased as the associative strength between members of a pair increased. Yet, other investigators (Barch, Lippman, \& Whalen, 1967; Eberlein \& Raskin, 1968; Fulkerson \& Kausler, 1969) have found that the group that receives related pairs does as well as the group that receives unrelated pairs. If recognition learning and verbal-discrimination learning involve the same processes, the attempt to determine whether or not associations influence recognition learning should be germane to the issue of whether or not verbal-discrimination learning is influenced by the associative strength between members of a pair. Moreover, the use of a PA task to manipulate associative strength has an advantage over the typical procedure of using related and unrelated word pairs in that all Ss receive the same recognition list. METHOD

A PA-to-recognition transfer design was used. All Ss received a list of 36PA pairs for six alternating study and test trials, followed by four alternating study and test recognition trials. All Ss received the same recognition list. A total of 105 students from undergraduate psychology courses at Michigan State University was assigned randomly to the seven groups so that there were $15 \mathrm{Ss}$ in each group. The groups differed with respect to the PA list they received prior to the recognition task.

The recognition test list was prepared by randomly selecting 144 words from a pool of 216 nouns so that 36 rows of four words each were obtained. One word in each row was randomly selected as the correct word. These 36 words will hereafter be referred to as the correct words; the 108 words not selected as correct for recognition will be referred to as the incorrect words. Words not used for the recognition task, but presented during PA learning, will be referred to as neutral words. A different random order of the correct words was used for each of the four recognition study trials. There were four random orders of the test list, with the restrictions that the same three incorrect words were always paired with the same correct word and the two words that were paired during PA learning were not presented in the same row.

The PA list for the C-C,N-N group was constructed by randomly pairing the 36 words that were correct for recognition (C-C pairs) and 36 words that were not presented during recognition (N-N pairs). The C-C,I-I group received the same 18 pairs of correct words plus 18 pairs obtained by randomly pairing 36 incorrect words (I-I pairs). The $\mathrm{C}-\mathrm{N}$ group received a list containing one correct word and one neutral word in each pair. The C-I group received one correct word and one incorrect word for each of the 36 pairs. The $\mathrm{N}-\mathrm{N}$ group received two neutral words in each pair. The N-N,I-I group received 18 pairs of neutral words and 18 pairs of incorrect words. The I-I group received two incorrect words in each pair.

The Ss were run in groups of from 4 to 21 . Each $S$ received two booklets, one for the
PA stage and one for the recognition stage. For the PA stage, the Ss were instructed to learn a list of 36 pairs of words so that when given one word from each pair they could recall the other word. They were given $108 \mathrm{sec}$ for each study trial and $108 \mathrm{sec}$ for each test trial. The study pages and test pages were presented alternately in the booklet. The test pages consisted of one word from each pair and a blank for $S$ to write the other member of the pair. There were two random orders of each PA study and test list, with the restriction that each word was a stimulus for three of the six test trials.

For the recognition phase, the Ss were told that they would be asked to learn a list of 36 words so that they could recognize them. They were given $18 \mathrm{sec}$ to study the words on each of the four study trials. Following each study trial, they were given $72 \mathrm{sec}$ to circle the correct word in each of the 36 rows of four words each that were presented on the test page. They were told to guess if they did not know the correct answer.

\section{RESULTS AND DISCUSSION}

The mean number of words correctly recalled for Trials 5 and 6 of PA learning and the four recognition trials is presented in Fig. 1. In general, the Ss achieved a relatively high level of PA performance by the later trials of PA learning. An analysis of variance on the total number of words recalled for the six trials of PA learning did not reveal any significant differences $[F(6,98)=1.68$, $p>.05]$. Since there is no reason to expect that the lists were of unequal difficulty, the

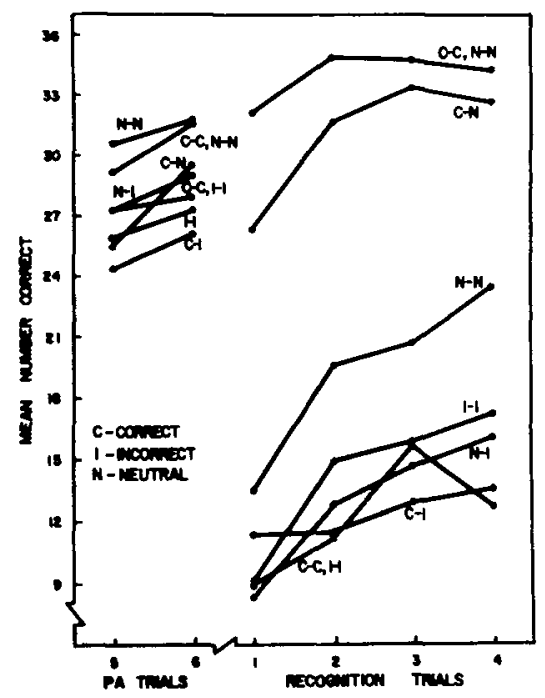

Fig. 1. The mean number of words correctly recalled for Trials 5 and 6 of PA learning and the four recognition trials for the seven conditions. The means for the recognition trials have been corrected for guessing. 
failure to find PA learning differences suggests that the learning ability of the seven groups did not differ.

In spite of the fact that all Ss were told to circle one word in each row for the recognition test trials, the Ss differed in their willingness to guess. Therefore, the scores were corrected for guessing by dividing the number of incorrect words circled by three and then subtracting the quotient from the number of words correctly circled. The means in Fig. 1 for the recognition trials have been corrected for guessing. An analysis of variance on the corrected scores for the four recognition trials revealed that there were significant differences $[F(6,98)=49.15, \mathrm{p}<.001]$. A Duncan's range test on these scores revealed that the $\mathrm{C}-\mathrm{C}, \mathrm{N}-\mathrm{N}$ group and the $\mathrm{C}-\mathrm{N}$ group did not differ significantly, but both groups were superior to the other five groups $(p<.001)$. The N-N group was superior to Groups I-I, $\mathrm{N}-\mathrm{I}, \mathrm{C}-\mathrm{I}$, and $\mathrm{C}-\mathrm{C}, \mathrm{I}-\mathrm{I}(\mathrm{p}<.01)$. No other differences were significant.

The control group for assessing whether positive or negative transfer was obtained is Group N-N. Positive transfer was obtained when correct words were presented and incorrect words were not presented during PA learning. It did not seem to matter whether associations were established between the 36 correct words or each correct word was associated with a neutral word during PA learning. Negative transfer was obtained when incorrect words were presented for PA learning. It did not seem to matter whether the incorrect words were paired with neutral, correct, or other incorrect words. In short, the associations formed during PA learning did not influence recognition learning.

One possible criticism of the present study is that there were not enough PAtrials for Ss to form "strong" associations. It could be argued that there were no differences between the C-C,N-N and C-N groups and the C-C,I-I and $\mathrm{C}$-I groups because the associations established during PA learning were too "weak" to have an effect on recognition learning. However, if this is a valid criticism, it follows that the correlation between PA and recognition performance should be lower for Groups C-N and C-I than for Groups C-C,N-N and C-C,I-I. The Ss in Groups C-N and C-I who had formed strong associations during PA leaming should have had a more difficult time on the recognition task than their counterparts in Groups C-C,N-N and C-C,I-I, if pairing a correct word with a neutral or incorrect word results in poorer recognition performance than pairing correct words with correct words. The correlation between the total number of words correctly recalled for the six PA trials and the number of words recognized on the first recognition trial (corrected for guessing) was .31, .07, .24, and .25 for Groups C-C,N-N, C-C,I-I, C-N, and C-I, respectively. These data afford no support for the view that associations influence recognition learning.

Although the present study gives added weight to the view that associations do not influence recognition, the issue of whether or not associations influence recognition seems to be as perplexing as it was prior to the present study. The issue is complicated by the fact that evidence from various sources can be considered relevant. That is, the study of verbal-discrimination learning with related and unrelated pairs (e.g. Palermo \& Ullrich, 1968), false-recognition rate with synonyms as filler words (e.g., Mandler, Pearlstone, \& Koopmans, 1969), and false recognitions produced by implicit associations (Underwood, 1965) all involve, in one way or another, the question of whether or not associations influence recognition. One could argue that the inconsistent findings conceming whether or not associations influence recognition are due to the various procedures and materials used. The task, therefore, is to vary materials and procedures systematically to determine what conditions are necessary for associations to influence recognition. On the other hand, if the influence of associative strength on recognition learning is dependent on the use of particular procedures and materials, one could argue that the finding is unlikely to be of great theoretical interest. Unless the effect of associations on recognition can be demonstrated under a variety of conditions, as is the case with recall, it seems more reasonable to conclude that recognition and recall involve different processes.

\section{REFERENCES}

BARCH, A. M., LIPPMAN, M., \& WHALEN, S. Intrapair relations in verbal-discrimination leaming: A paradoxical finding. Paper read at the Midwestem Psychological Association meeting, Chicago, 1967.

BOWER, G. H., CLARK, M.C., LESGOLD, A.M., \& WINZENZ, D. Hierarchical retrieval schemes in recall of categorized word lists. Joumal of Verbal Learning \& Verbal Behavior, 1969, 8, 323-343.

EBERLEIN, E., \& RASKIN, D. C. Intrapair and interpair associations in verbal discrimination learning. Psychonomic Science, 1968, 11, 145-146.

EKSTRAND, B. R., WALLACE, W. P., \& UNDERWOOD, B. J. A frequency theory of verbatdiscrimination leaming. Psychological Review, 1966, 74, 566-578.

FULKERSON, F. E., \& KAUSLER, D. H. Effects of intrapair and interpair bidirectional associates on verbal-discrimination learning. Journal of Verbal Learning \& Verbal Behavior, $1969,8,307-310$.

KINTSCH, W. Recognition and free recall of organized lists. Joumal of Experimental Psychology, 1968, 78, 481-487.

MANDLER, G., PEARLSTONE, Z., \& KOOPMANS, H. S. Effects of organization and semantic similarity on recall and recognition. Journal of Verbal Learning \& Verbal Behavior, $1969,8,410-423$.

PALERMO, D. S., \& ULLRICH, J. R. Verbal discrimination learning as a function of associative strength between the word-pair members. Journal of Verbal Learning \& Verbal Behavior, 1968, 7, 945-952.

UNDERWOOD, B. J. False recognition produced by implicit verbal responses. Journal of Experimental Psychology, 1965, 70, 122-129.

WOOD, G. Higher order memory units and free recall leaming. Journal of Experimental Psychology, 1969, 80, 286-288.

NOTE

1. This investigation was supported by Grant MH 16991 from the National Institute of Mental Health and by a Biomedical Sciences Support grant from Michigan State University. Thanks are due to Joyce Pennington and Susan Purcell. 